\title{
Effect of lithium doping on the evolution of rheological and structural properties during gelation of siloxane-poly(oxypropylene) nanocomposites $\dagger$
}

\author{
Received 18th April 2005, Accepted 1st July 2005 \\ First published as an Advance Article on the web 1st August 2005 \\ DOI: $10.1039 / b 505462 c$
}

V. H. V. Sarmento, K. Dahmouche, ${ }^{*}$ S. H. Pulcinelli and C. V. Santilli

The influence of lithium doping on the evolution of viscoelastic properties and structure during the gelation of siloxane-poly(oxypropylene) (PPO) nanocomposites has been studied. For several $[\mathrm{O}] /[\mathrm{Li}]$ ratios ( $\mathrm{O}$ being the oxygen of the ether-type), dynamic rheological measurements allowed us to follow the evolution of storage and loss moduli, complex viscosity and phase angle during gelation of $\mathrm{Li}^{+}$-doped hybrid sols. All samples exhibit a Newtonian viscous character in the initial step of the process and are progressively transformed into viscoelastic gels. The evolution of the rheological properties of these systems allowed us to determine the aggregation mechanisms of silicon species present in hybrid sols, which lead to sol-gel transformation: mass fractal growth and nearly linear growth at the beginning of gelation, and percolation at the final stage of the process. The influence of doping on the aggregation mechanisms depends on the polymer molecular weight: while for hybrids containing long polymer chains $\left(M_{\mathrm{w}}=4000 \mathrm{~g} \mathrm{~mol}^{-1}\right)$ gelation occurs in the initial stages through diffusion-limited monomer-cluster aggregation (DLMCA) for all doping levels, this mechanism is only observed for hybrids containing short chains $\left(M_{\mathrm{w}}=130 \mathrm{~g} \mathrm{~mol}^{-1}\right)$ at low lithium concentration $([\mathrm{O}] /[\mathrm{Li}]=80)$. For undoped and high doped siloxane- $\mathrm{PPO}_{130}$ composites $([\mathrm{O}] /[\mathrm{Li}]=4)$, cluster-cluster aggregation is the predominant mechanism occurring at the initial gelation stages. The nature and the proportion of the different coordination sites for lithium cations in the hybrid sols, determined by ${ }^{7} \mathrm{Li} \mathrm{NMR}$ and infrared spectroscopy, affect the aggregation mechanisms during gelation and the condensation degree of the siloxane phase in the final dried materials.

\section{Introduction}

Up to now, most of the rheological studies devoted to sol-gel derived materials concern inorganic networks obtained from silicon $^{1-3}$ or transition metal alkoxides. ${ }^{4,5}$ In spite of the fascinating electrochemical, biological, electrical, and optical properties of organic-inorganic hybrid materials resulting from the interpenetration of the two phases at the nanometric scale, ${ }^{6}$ only few works concerning the rheological aspects of the sol-gel transformation of hybrids and nanocomposites have been reported. ${ }^{7,8}$

Over the last decade, ${ }^{9-12}$ we have investigated the structure and electrical properties of siloxane-poly(oxypropylene) nanocomposites, in which the organic and inorganic phases are bonded by urea bridges. These transparent and flexible materials belong to the family of ureasils which also includes siloxane-poly(oxyethylene) hybrids (originally synthesized to be used as protonic conductors ${ }^{13}$ and in photochromic devices). ${ }^{14}$ The presence of the covalent bonds between the polymer and the siloxane backbone hinders phase separation and preserves the stability of mechanical and thermal properties of ureasils. Another interest of this family of hybrids is their potential to form good solid ionic conductors by

Instituto de Química-UNESP, P.O. Box 355 CEP 14800-900

Araraquara, SP,Brazil.E-mail: karim@ima.ufrj.br;

Fax: 5521227013 17; Tel: 552125627766

$\uparrow$ Electronic supplementary information (ESI) available: time evolution of reactions. See http://dx.doi.org/10.1039/b505462c dissolving alkaline salts in siloxane-poly(oxyethylene) and siloxane-poly(oxypropylene) matrixes. ${ }^{9,11,12}$ Recently, an electrochromic device using these type of 'ormolytes' (organically modified electrolytes) was elaborated. ${ }^{15}$

In a recent paper $^{16}$ we have investigated the evolution of rheological properties of undoped siloxane-poly(oxypropylene) composites during gelation. This study revealed that hybrid sols are transformed in wet gels through several aggregation mechanisms (mass fractal growth, nearly linear growth and percolation), which may occur at different gelation stages, depending on the $\mathrm{pH}$ of the sol and the molecular weight of the polymer. On the other hand, SAXS studies performed on undoped dried gels ${ }^{10}$ revealed that these hybrids are formed by a poly(ether) matrix, in which spatially correlated siloxane particles are embedded. The doping of these systems by lithium ions leads to the increase in matrix density due to the coordination of cations to ethertype oxygen of the polymer chains. At high doping levels $([\mathrm{O}] /[\mathrm{Li}]<15)$ the observed diminution of the siloxane interparticle distance was associated with a contraction of the polymer phase promoted by $\mathrm{O}-\mathrm{Li}^{+}-\mathrm{O}$ crosslinks between ether-type oxygen atoms of different PPO chains and lithium ions. These crosslinks promote an increase in chain rigidity leading to a decrease of ionic mobility and conductivity. ${ }^{10}$ Furthermore, an increase of average siloxane particle radius measured in doped samples was attributed to more efficient polycondensations reactions between silicon species promoted by doping. ${ }^{10}$ 
In order to determine the origin of the structural and electrical properties differences between dried nanocomposites prepared with different doping level, it is of fundamental importance to understand how the addition of alkaline salts affects the aggregation mechanisms involved in the hybrids network formation. In this work the viscoelastic properties of lithium-doped siloxane-poly(oxypropylene) nanocomposites (siloxane-PPO) were measured in situ during the sol-gel transformation. The results were analysed by using the linear aggregate growth, mass fractal growth ${ }^{17}$ and scalar percolation $^{18}$ models. Quasi-elastic light scattering (QELS) measurements were performed to determine the growth rate constant of aggregates during the initial step of gelation, which was correlated to the evolution of rheological properties. The evolution of the fraction of lithium ions coordinated in different sites was investigated by ${ }^{7} \mathrm{Li} \mathrm{NMR}$ and Fouriertransform infrared (FTIR) spectroscopy during gelation. The influence of the lithium concentration upon the gelation mechanism in two hybrid sols containing PPO of low $\left(130 \mathrm{~g} \mathrm{~mol}^{-1}\right)$ and high $\left(4000 \mathrm{~g} \mathrm{~mol}^{-1}\right)$ molecular weight was investigated. In order to minimize the effect of nucleophilic attack of protonated $(\mathrm{pH}<2)$ and deprotonated $(\mathrm{pH}>2)$ silanol species involved in the acid and base catalyzed condensation mechanisms, and therefore study the effective influence of lithium contents on the aggregation mechanism, all sols were prepared at $\mathrm{pH}=2.5$, which is a value close to the isoelectric point of silica $(\mathrm{pH}=2.2) .{ }^{19}$

\section{Experimental}

\subsection{Samples preparation}

The preparation of siloxane-PPO hybrid sols and gels from commercially available reagents (Fluka, Aldrich) has already been described. ${ }^{9}$ Succinctly, 3-isocyanatopropyltriethoxysilane (IsoTrEOS) and $O, O^{\prime}$-bis(2-aminopropyl)poly(oxypropylene) in the molar ratio $2: 1$ were stirred together in tetrahydrofuran (THF) under reflux at $80{ }^{\circ} \mathrm{C}$ for $6 \mathrm{~h}$. THF was then evaporated and a hybrid precursor $(\mathrm{EtO})_{3} \mathrm{Si}\left(\mathrm{CH}_{2}\right)_{3} \mathrm{NHCONHCH}-$ $\left(\mathrm{CH}_{3}\right) \mathrm{CH}_{2}-(\mathrm{PPO})_{n} \mathrm{NHCONH}\left(\mathrm{CH}_{2}\right) \mathrm{Si}(\mathrm{OEt})_{3} \quad(n=$ polymer molecular weight) was obtained. A $0.5 \mathrm{~g}$ sample of this precursor was mixed with $0.8 \mathrm{~mL}$ of ethanol containing $\mathrm{HCl}$ $([\mathrm{HCl}] /[\mathrm{Si}]=0.08)$, used to catalyse the hydrolysis reaction. Then, desired amounts of lithium perchlorate $\left(\mathrm{LiClO}_{4}\right)$ corresponding to two doping levels $([\mathrm{O}] /[\mathrm{Li}]=80$ and 4$)$ were dissolved in this solution. Finally, $0.2 \mathrm{~mL}$ of water was added upon stirring to promote the hydrolysis and polycondensation reactions of the hybrid precursor, forming a gel after a few hours. The wet gels were slowly dried under vacuum at $80{ }^{\circ} \mathrm{C}$ for $24 \mathrm{~h}$ to perform ${ }^{29} \mathrm{Si}$ NMR measurements. Hybrid samples prepared with PPO molecular weight 130 and $4000 \mathrm{~g} \mathrm{~mol}^{-1}$ are labelled as $\mathrm{PPO}_{130}$ and $\mathrm{PPO}_{4000}$, respectively.

\subsection{Experimental techniques}

The time evolution of the viscoelastic properties during the gelation process was followed by dynamic oscillatory measurements carried out with a controlled-stress rheometer (CarriMed-CLS 100), equipped with cone-plate tools of $60 \mathrm{~mm}$ diameter, with a gap of $28 \mu \mathrm{m}$. A frequency sweep from 0.10 to
$0.33 \mathrm{~Hz}$ of the oscillatory applied stress was used, because higher frequencies influences the gelation time, while the lower ones involve measurement times unable to get along with kinetic studies. ${ }^{20}$ The systematic error in frequency given by the rheometer was around $0.01 \mathrm{~Hz}$. The applied stress was fixed at $0.8 \mathrm{~Pa}$ during the first stages of gelation and increased to $2 \mathrm{~Pa}$ near the gel point. The temperature was kept constant at $20{ }^{\circ} \mathrm{C}$ by means of a Peltier device. The size of the points used to plot the measured storage $\left(G^{\prime}\right)$ and loss $\left(G^{\prime \prime}\right)$ moduli, complex viscosity $\left(\eta^{*}\right)$ and phase angle $(\delta)$ was always larger than the random error in these parameter values.

In situ QELS measurements were performed during gelation at $20{ }^{\circ} \mathrm{C}$ using a solid-state laser $(25 \mathrm{~mW}, \lambda=532 \mathrm{~nm})$, a goniometer BI200SM and a photocorrelator (Brookhaven PCS100). The error in the effective particle diameter measured during the experiment was around $5 \%$.

Solid-state ${ }^{7} \mathrm{Li}(I=3 / 2)$ nuclear magnetic resonance (NMR) spectra were recorded in situ during hybrid gelation in a spectrometer (VARIAN) operating at $300 \mathrm{MHz}$ and $7.05 \mathrm{~T}$; the Larmor frequency for ${ }^{7} \mathrm{Li}$ was $116.575 \mathrm{MHz}$. The spectra were obtained from the Fourier transform of the free induction decays (FID), following a single $\pi / 2$ excitation pulse and a dead time of $5 \mathrm{~s}$. Proton decoupling was always used during acquisition of ${ }^{7} \mathrm{Li}$ spectra. Chemical shifts were determined using a $\mathrm{LiCl} 1 \mathrm{M}$ aqueous solution as reference. To evaluate the complex band envelope, which appears in the NMR spectra, and to identify the underlying component band, the curve-fitting procedure in the Peakfit software was used.

Solid-state ${ }^{29} \mathrm{Si}(I=1 / 2)$ magic-angle spinning-nuclear magnetic resonance (MAS-NMR) spectra were recorded for the dried gels of same composition using the equipment described above and a rotation of $4.5 \mathrm{kHz}$. The Larmor frequency for ${ }^{29} \mathrm{Si}$ was $59.59 \mathrm{MHz}$. The spectra were obtained from the Fourier transform of the free induction decays (FID) following a single $\pi / 2$ excitation pulse and a dead time of $30 \mathrm{~s}$. Chemical shifts were referenced to tetramethylsilane used as external standard. Proton decoupling was always used during the spectra acquisition and the uncertainty in chemical shift values was less than $0.2 \mathrm{ppm}$.

Mid-infrared spectra were acquired at room temperature during gelation using a FTIR spectrometer (Spectrum 2000, Perkin-Elmer). The spectra were recorded over the range 400 $2000 \mathrm{~cm}^{-1}$ by averaging 16 scans at a maximum resolution of $4 \mathrm{~cm}^{-1}$. A small amount of liquid sample $(1 \mathrm{~mL})$ was deposited on a dried spectroscopic grade potassium bromide $(\mathrm{KBr}$, Merck). A linear baseline was assumed in all cases in the frequency ranges where no significant absorption was detected. The interval between each measurement was $20 \mathrm{~min}$ and the initial time corresponds to water addition in the reaction bath.

\section{Results}

\subsection{General gelation behavior}

Fig. 1 shows the typical time evolution of the storage $\left(G^{\prime}\right)$ and loss $\left(G^{\prime \prime}\right)$ moduli, complex viscosity $\left(\eta^{*}\right)$, and phase angle $(\delta)$ for the $\mathrm{PPO}_{4000}$ doped with high lithium contents $([\mathrm{O}] /[\mathrm{Li}]=4)$. Irrespective of the lithium contents or the PPO molecular weight, the shape of the curves was essentially the same for all the hybrids. Three distinct temporal regimes could be resolved: 


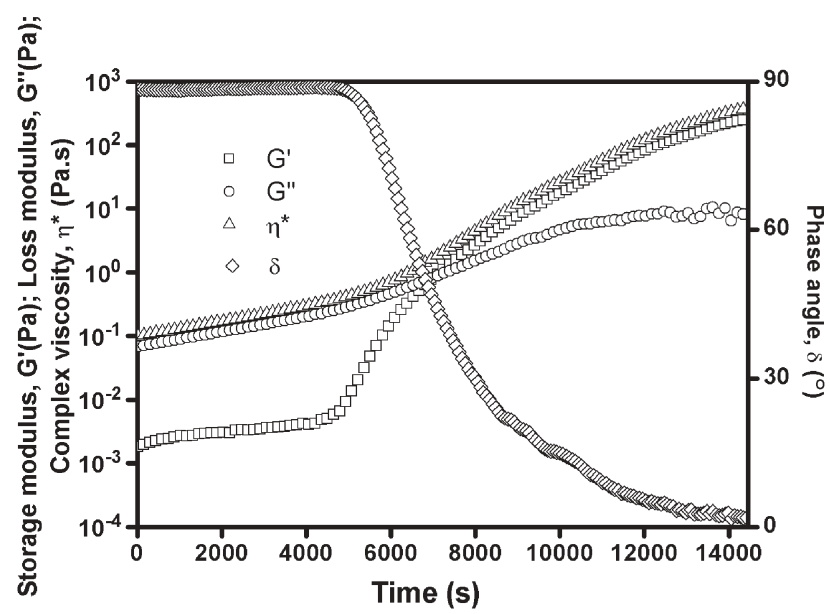

Fig. 1 Time evolution of storage $\left(G^{\prime}\right)$ and loss $\left(G^{\prime \prime}\right)$ moduli, complex viscosity $\left(\eta^{*}\right)$ and phase angle $(\delta)$ during the sol-gel transition of $\mathrm{PPO}_{4000}$ hybrid with $[\mathrm{O}] /[\mathrm{Li}]=4$.

(i) During the initial stage $(t<4800 \mathrm{~s})$, the phase angle $(\delta)$ is constant and close to $90^{\circ}$, the viscous modulus $G^{\prime \prime}$ increased slowly, while $G^{\prime}$ (storage modulus) is two orders of magnitude lower than $G^{\prime \prime}$. These properties are typical of a viscous fluid in which each particle or chain does not interact with its neighbours. The slow increase of $G^{\prime \prime}$ and viscosity, $\eta^{*}$, indicates a growth of the aggregate or particles size due to the occurrence of the polycondensation reactions between hydrolysed silicon species. (ii) In the intermediate stage $(4800<t<$ $12000 \mathrm{~s}), G^{\prime}$ increases faster and exceeded $G^{\prime \prime}$, while $\delta$ decreases to a value near to $0^{\circ}$. This increase of $G^{\prime}$ is characteristic of the transformation from a Newtonian fluid to an elastic solid due to network formation. ${ }^{21}$ (iii) During the last stage $(t>12000 \mathrm{~s})$ $G^{\prime}$ continues to increase with time due to gel aging, while $G^{\prime \prime}$ is almost invariant and less than $G^{\prime}$, showing the dominant elasticity of the system and indicating the existence of a permanent three-dimensional network.

The aggregate growth, indicated by the increase of viscosity during the initial stage of sol-gel transformation, was confirmed by the evolution of the effective hydrodynamic diameter of particles, $d$, measured by QELS. Fig. 2 shows the logarithmic plot of $\mathrm{d}(t)$ (normalized by the initial effective diameter of particles $d_{0}$ ) as a function of reaction time for $\mathrm{PPO}_{4000}$ and $\mathrm{PPO}_{130}$ hybrids doped with low $([\mathrm{O}] /[\mathrm{Li}]=80)$ and high $([\mathrm{O}] /[\mathrm{Li}]=4)$ lithium contents. The linear dependence shown by the straight line obtained from least square fitting (with a correlation coefficient of 0.995 ) is in agreement with

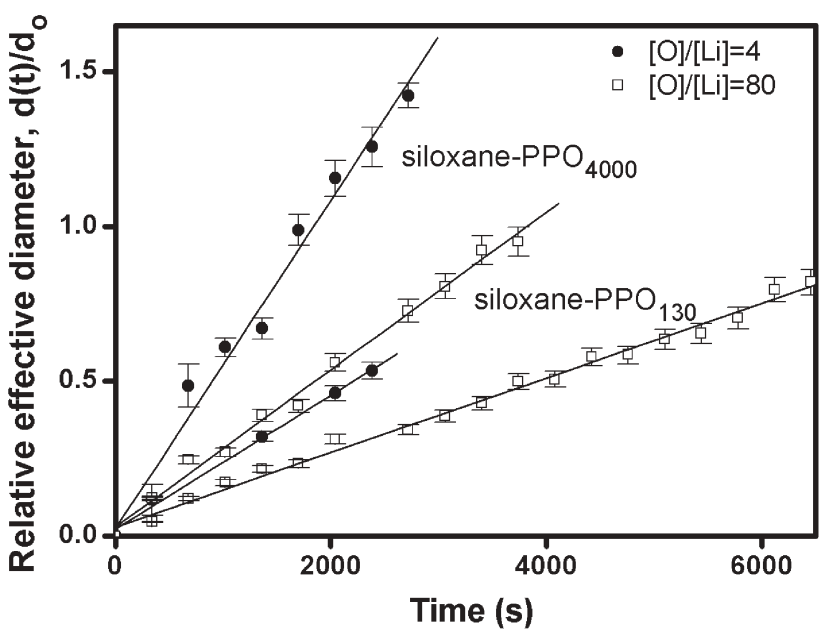

Fig. 2 Time evolution of effective diameter over the initial effective diameter $\left(d / d_{0}\right)$ obtained by QELS measurements. Continuous lines show the least square fitting of eqn (1) for data corresponding to $\mathrm{PPO}_{130}$ and $\mathrm{PPO}_{4000}$ hybrids prepared with $[\mathrm{O}] /[\mathrm{Li}]=4$ and 80 .

the exponential growth relationship found by Cannel and Auberts for silica sols: ${ }^{22}$

$$
\frac{d(t)}{d_{0}}=\exp (r t)
$$

where the aggregate growth rate, $r$, is given by the slope of the linear function. It was observed that the larger the PPO molecular weight $\left(4000 \mathrm{~g} \mathrm{~mol}^{-1}\right)$ the larger the $r$-value (Table 1). On the other hand, for both $\mathrm{PPO}_{130}$ and $\mathrm{PPO}_{4000}$, the $r$-value (Table 1) for the low-doped sample $([\mathrm{O}] /[\mathrm{Li}]=80)$ is lower than that observed for the high doped one $([\mathrm{O}] /[\mathrm{Li}]=4)$. Furthermore, for a defined PPO molecular weight, the doped composites presented lower $r$-values (Table 1) than the undoped samples.

The pronounced increase of the storage moduli during the intermediate gelation stage is characteristic of the sol-gel transition. $^{21}$ The gel time $\left(t_{\mathrm{gel}}\right)$ observed in this region is of importance both in materials processing and for applications of current sol-gel transition models. ${ }^{17}$ The definition of $t_{\text {gel }}$ has been the subject of several discussions concerning both theoretical and experimental determinations, and the most accepted criterion is the one proposed by Winter et al. ${ }^{23}$ They proposed that the tangent of the phase angle $(\tan \delta)$ is independent of the oscillatory frequency $(\omega)$ at $t_{\text {gel }}$. Thus, the curves showing the time evolution of $\tan \delta$ measured at several frequencies should intersect at a critical time, which defines the

Table 1 Gel time, aggregate growth rate $(r)$, fractal dimensionality $(D), \mathrm{T}^{3} / \mathrm{T}^{2}$ ratio, condensation degree and critical exponent values $(\mu$ and $\kappa)$ obtained for $\mathrm{PPO}_{130}$ and $\mathrm{PPO}_{4000}$ hybrids with different doping levels

\begin{tabular}{|c|c|c|c|c|c|c|c|c|}
\hline $\begin{array}{l}\text { PPO molecular } \\
\text { weight/g mol }\end{array}$ & {$[\mathrm{O}] /[\mathrm{Li}]$} & $t_{\mathrm{gel}} / \mathrm{s}$ & $10^{4} \times r / s^{-1}$ & $D$ & $\begin{array}{l}\mathrm{T}^{3} / \mathrm{T}^{2} \text { area } \\
\text { ratio }\end{array}$ & $\begin{array}{l}\text { Condensation } \\
\text { degree }(\%)\end{array}$ & $\mu$ & $\kappa$ \\
\hline 130 & 4 & 11950 & $2.5 \pm 0.1$ & $1.8 \pm 0.1$ & $2.0 \pm 0.1$ & $89 \pm 1$ & $1.9 \pm 0.1$ & $0.7 \pm 0.2$ \\
\hline 130 & 80 & 12500 & $1.2 \pm 0.1$ & $2.4 \pm 0.1$ & $1.7 \pm 0.1$ & $87 \pm 1$ & $1.9 \pm 0.1$ & $0.7 \pm 0.2$ \\
\hline 130 & Undoped $^{16}$ & 5771 & $2.7 \pm 0.1$ & $2.1 \pm 0.1$ & $0.7 \pm 0.1$ & $80 \pm 2$ & $2.0 \pm 0.1$ & $0.7 \pm 0.1$ \\
\hline 4000 & 4 & 6600 & $5.3 \pm 0.1$ & $2.4 \pm 0.1$ & $3.5 \pm 0.1$ & $93 \pm 1$ & $1.9 \pm 0.2$ & $0.7 \pm 0.2$ \\
\hline 4000 & 80 & 9000 & $4.9 \pm 0.1$ & $2.4 \pm 0.1$ & $3.3 \pm 0.1$ & $92 \pm 2$ & $1.9 \pm 0.1$ & $0.7 \pm 0.1$ \\
\hline 4000 & Undoped $^{16}$ & 2539 & $8.8 \pm 0.7$ & $2.4 \pm 0.1$ & $3.0 \pm 0.3$ & $92 \pm 2$ & $1.9 \pm 0.1$ & $0.8 \pm 0.1$ \\
\hline
\end{tabular}


$t_{\text {gel }}$. However, our experimental curves have shown a dispersion of this crossover due to random errors, so that the use of standard deviation $(s)$ of the mean $<\tan \delta>$ measured in a frequency sweep was a more convenient statistical tool to find $t_{\mathrm{gel}}$. In this case, the $t_{\mathrm{gel}}$ is defined as the time corresponding to the minimum of the curve $\log (s /<\tan \delta>)$ as a function of reaction time. ${ }^{24}$

Observation of the time evolution of $\log (s /<\tan \delta>)$ versus reaction time for $\mathrm{PPO}_{130}$ and $\mathrm{PPO}_{4000}$ samples doped with $[\mathrm{O}] /[\mathrm{Li}]=80$ and 4 (refer to the supplementary material) shows that hybrids containing PPO of large molecular weight present the shortest gel time (Table 1). On the other hand, for both $\mathrm{PPO}_{4000}$ and $\mathrm{PPO}_{130}$ the gelation time of the low-doped sample $([\mathrm{O}] /[\mathrm{Li}]=80)$ is longer $($ Table 1$)$ than that observed for the high-doped one $([\mathrm{O}] /[\mathrm{Li}]=4)$. Lastly, for a defined PPO molecular weight, the doped composites present longer $t_{\mathrm{gel}}$ (Table 1) than undoped samples.

\subsection{Aggregate growth mechanism}

The slow increase of the viscous modulus, complex viscosity (Fig. 1) and effective hydrodynamic diameter of aggregates (Fig. 2) should be related to the increase in the molecular weight of reactive species during gelation. Since the only reactions occurring during this process are hydrolysis and condensation of the hybrid precursor, we can assume that this evolution is due to the progressive crosslinking of different PPO chains through siloxane species located at the chain end. Further increase in elasticity would come from the formation and consolidation of a three-dimensional network (hybrid clusters) due to the same reactions. In an attempt to understand the mechanism of formation and growth of the hybrid network, theoretical models were applied to the experimental data.

Two alternative models proposed by Pope and Mackenzie ${ }^{17}$ to describe the time evolution of viscosity during the sol-gel transition are the "nearly linear growth model" (NLGM) and the "mass fractal growth model" (MFGM). The former is applied to nearly linear growth of aggregates or macromolecules, in which the degree of crosslinking may be neglected. The second is able to describe the evolution of a system in which a high degree of crosslinking occurs. The latter case is usually taken as a typical fractal theory problem. ${ }^{19}$ Both models predict the viscosity-time dependence as a linear relationship. Hence, it is possible in principle to distinguish between a linear and a branched growth, by plotting the viscosity versus time. Another model that can be applied is the scalar percolation theory, proposed by De Gennes ${ }^{18}$ to describe the divergence of many properties near the sol to gel transition, when the first infinite cluster is formed.

3.2.1 Fractal growth regime. The MFGM describes the increase of the specific viscosity during growth of fractal aggregates with dimensionality $D$, according to: ${ }^{17}$

$$
\ln \left(\eta_{s p}\right)=\ln \left(\frac{Q L}{\rho_{0}}\right)+(3-D) r t
$$

where $\eta_{s p}=\frac{\eta^{*}-\eta_{0}}{\eta_{0}}$ is the specific viscosity, $\eta_{0}$ is the solvent viscosity, $L$ a geometrical shape constant, $r$ the growth rate
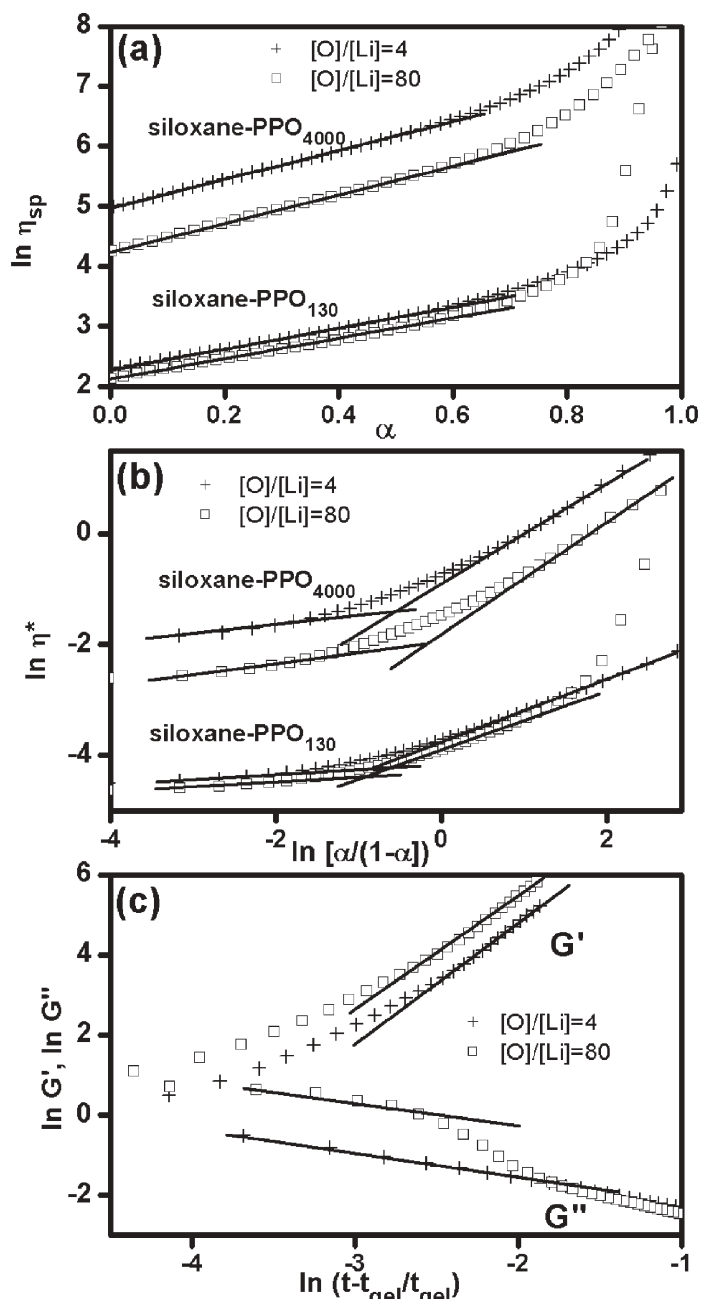

Fig. 3 Complex viscosity $\left(\eta^{*}\right)$, specific viscosity $\left(\eta_{\mathrm{sp}}\right)$ and storage $\left(G^{\prime}\right)$ and loss $\left(G^{\prime \prime}\right)$ moduli plotted in the coordinates of fractal (a) and nearly linear (b) growth models, and percolation scaling (c) coordinates. Continuous lines show the least square linear fits of experimental data corresponding to $\mathrm{PPO}_{130}$ and $\mathrm{PPO}_{4000}$ hybrids prepared with $[\mathrm{O}] /[\mathrm{Li}]=$ 4 and 80 . For clarity, only the data corresponding to $\mathrm{PPO}_{4000}$ hybrids are presented in (c).

constant, $\rho_{0}$ and $Q$ are the density and the mass concentration of monomer constituting the fractal clusters, respectively.

The logarithm of the specific viscosity as a function of the reduced time $\left(\alpha=t / t_{\mathrm{gel}}\right)$ for $\mathrm{PPO}_{130}$ and $\mathrm{PPO}_{4000}$ hybrids doped with low $([\mathrm{O}] /[\mathrm{Li}]=80)$ and high $([\mathrm{O}] /[\mathrm{Li}]=4)$ lithium contents exhibit the linear dependence predicted by eqn (2) in the initial stage of gelation (Fig. 3a). The least square fitting with a correlation coefficient $>0.998$ recovers the range of $\alpha<0.63$ for all samples, indicating that mass fractal growth occurs in the initial stage of the sol-gel transformation. Under these conditions, eqn (2) establishes that the fractal dimensionality of aggregates can be determined from the slope of the straight lines (Fig. 3a) and using the growth rate values (Table 1). A $D$ value around 2.4 was obtained for $\mathrm{PPO}_{4000}$ at both doping levels, while for $\mathrm{PPO}_{130} D$ decreases from 2.4 to 1.8 as $[\mathrm{O}] /[\mathrm{Li}]$ decreases from 80 to 4 .

It is interesting to compare these values with the ones obtained for undoped hybrids prepared at same conditions, i.e. 
2.4 and 2.1 for $\mathrm{PPO}_{4000}$ and $\mathrm{PPO}_{130}$, respectively. ${ }^{16}$ The $D$ value for the undoped $\mathrm{PPO}_{130}$ hybrid characterizes a gelation process controlled by reaction limited cluster-cluster aggregation $\left(\mathrm{RLCCA}^{19}\right)$, in which the rate of condensation is smaller than the rate of hydrolysis, which usually occurs at $\mathrm{pH}$ near the isoelectric point of silica ( $\mathrm{pH} c a .2 .2)$. The increase of $D$ from 2.1 to 2.4 for the low-doped sample $([\mathrm{O}] /[\mathrm{Li}]=80)$ reveals a modification of the aggregation mechanism from RLCCA to DLMCA (diffusion limited monomer-cluster aggregation). The existence of such a mechanism is usually reported for gelation of silicon alkoxides under neutral and basic conditions ${ }^{19}$ and results in a continuous source of unhydrolysed or poorly hydrolysed silicon reactive species (monomers) and a high condensation rate, leading to high polycondensed silicon species.

For the highest doped siloxane- $\mathrm{PPO}_{130}$ sol $([\mathrm{O}] /[\mathrm{Li}]=4)$ the diffusion limited cluster-cluster aggregation (DLCCA) ${ }^{19}$ mechanism is revealed by the fractal dimensionality of 1.8. Such a mechanism occurs when the hydrolysis reaction is completed far away from the gel point and the polycondensation reactions occur slowly. Based on the fractal dimensionality $(D=2.4)$ obtained for the $\mathrm{PPO}_{4000}$ hybrids we suggest the preponderance of a DLMCA mechanism. This mechanism has already been observed from the fractal dimensionality $(D=$ 2.4) determined by SAXS measurements during the first stage of gelation of undoped $\mathrm{PPO}_{2000}$ hybrids prepared under similar $\mathrm{pH}$ conditions. ${ }^{25}$

3.2.2 Linear growth regime. The NLGM combines the gelation kinetics equation proposed by Bechtold ${ }^{26}$ and Flory's equation $^{27}$ for viscosity of linear polymers to yield:

$$
\ln \left(\eta^{*}\right)=\ln A+m \ln \Omega+m \ln (\alpha /(1-\alpha))
$$

where $A$ and $m$ are constants, $\alpha$ is the reduced time of gelation $\left(t / t_{\mathrm{gel}}\right)$ and $\Omega$ is related to the initial molecular weight of hybrid precursor $\left(M_{0}\right)$, and to the functionality $(f)$ of gelation species by:

$$
\Omega=\frac{2 M_{0}}{f-2}
$$

Thus a linear growth should be represented by a linear function in the plot of $\ln \left(\eta^{*}\right)$ as a function of $\ln (\alpha /(1-\alpha))$, and the functionality $(f)$ of the polymerizing species can be calculated from the intercept of viscosities at $\alpha=0.5$.

Fig. $3 \mathrm{~b}$ shows the time evolution of the viscosity using natural logarithmic coordinates of NLGM for siloxane$\mathrm{PPO}_{130}$ and siloxane- $\mathrm{PPO}_{4000}$ hybrids at both doping levels. The trend followed by the data is similar to that observed for undoped samples prepared at same $\mathrm{pH}$ conditions, ${ }^{16}$ so that curves could be approximated by two linear parts. It is interesting to note that the region between these linear steps corresponds to the upper $\alpha$-limit of fractal growth regime verified in Fig. 3a. For the initial time period, the least square fitting of a linear function (continuous lines in Fig. 3b) and the intercept $\alpha=0.5$ yields a functionality of $2 \pm 0.0005$, for all the samples. Based on these results and those of Fig. 3a we suggest a simultaneous occurrence of nearly linear and fractal growth during the first stage of sol-gel transition. However, this finding has physical meaning only for $D=1$, and the fractal dimensionality between 2.1 and 2.4 , calculated from the fractal growth model, indicates the growth of ramified molecules. In attempting to interpret this apparent inconsistency, it must be recognized that (i) the initial polymerisation of dimers, trimers and even tetramers, is likely to mimic linear growth and (ii) each silicon species bonded at the end of PPO chain contains three reactive groups. Thus the functionality of 2 can result in branched structure if the bonding of momeric units to two hydrolysed groups of the same silicon site occurs. Due to the linear shape of the monomeric hybrid precursor, the development of branched clusters with $f=2$ can be a consequence of the presence of longer linear PPO chains of the hybrid precursor.

The second linear step observed in the later time period allows also the use of NLGM to estimate the functionality of polymerisation or aggregation. This approach yields a functionality of $2.40 \pm 0.05$ and $2.70 \pm 0.05$, respectively, for $\mathrm{PPO}_{4000}$ and $\mathrm{PPO}_{130}$ doped with low lithium contents $([\mathrm{O}] /[\mathrm{Li}]=80)$. These numbers indicate that the growth is not linear. This feature results from the interconnection between aggregates to form the continuous gel network structure. We will show in the following that the evolution of dynamic mechanical properties of hybrids in this region can be described by the percolation theory. Otherwise, absurd functionalities $(f>5)$ have been calculated for the second linear region (Fig. 3b) corresponding to the same hybrids doped at high concentrations $([\mathrm{O}] /[\mathrm{Li}]=4)$. This behaviour should be due to the formation of crosslinks $\mathrm{O}-\mathrm{Li}^{+}-\mathrm{O}$ between lithium ions and ether-type or carbonyl-type oxygen of different PPO chains belonging to different fractal aggregates, as observed in previous studies. ${ }^{10}$ These crosslinks lead to the polymer phase shrinkage resulting in the formation of more compact structures that should present a large apparent functionality.

3.2.3 Percolation regime. Percolation theory ${ }^{18}$ describes the divergence of many properties near the transition from the sol (finite branched cluster) to the gel, when an infinite cluster is formed. Universal scaling laws have been predicted for the loss, $G^{\prime \prime}$, and storage, $G^{\prime}$ moduli near to the gel point, i.e.:

$$
\begin{gathered}
G^{\prime \prime}(p) \approx\left(\frac{p_{c}-p}{p_{c}}\right)^{-\kappa} \text { for } p<p_{c} \\
G^{\prime}(p) \approx\left(\frac{p-p_{c}}{p_{c}}\right)^{\mu} \text { for } p>p_{c}
\end{gathered}
$$

where the control parameter, $p$, is proportional to the fraction of reacted species or formed bonds, and $p_{\mathrm{c}}$ is a critical parameter corresponding to the threshold, where the first infinite cluster appears. The critical exponents, $\kappa$ and $\mu$, are expected to be universal and independent on the specificity of the gelling system. In practice, viscoelastic measurements of the gels give different values for $\kappa$ and $\mu$, depending on the system. ${ }^{28}$ For chemical gels, in which the reaction proceeds regularly with time the ratio, $\left(p-p_{\mathrm{c}}\right) / p_{\mathrm{c}}$, is generally replaced by $\left(\left(t-t_{\text {gel }}\right) / t_{\text {gel }}\right)$ near the critical gelation time, $t_{\text {gel. }}{ }^{28}$

Fig. 3c shows a natural logarithmic plot of $G^{\prime}$ and $G^{\prime \prime}$ versus $\left(\left(t-t_{\text {gel })} / t_{\text {gel }}\right)\right.$ for $\mathrm{PPO}_{4000}$ hybrids doped with $[\mathrm{O}] /[\mathrm{Li}]=80$ and 
4. The shape of the curves was essentially the same for $\mathrm{PPO}_{130}$ hybrids. The curves are very close to one another, revealing that the gelation mechanism near the gel point $(\alpha>0.9)$ is essentially independent of the lithium content. The continuous lines represent the least square linear fitting of eqn (5) and (6), which establish that the exponents $\mu$ and $\kappa$ could be calculated from the slope of the resulting linear curves. The values of both exponents for all samples are presented in Table 1 and agree with the numerical results for electrical percolation of a network proposed by de Gennes (namely $\mu=1.94$ and $\kappa=$ 0.75). ${ }^{18}$ Therefore, we conclude that the last stages of gelation process consist on scalar percolation between fractal hybrid aggregates formed during the initial stages.

\subsection{Degree of siloxane condensation}

In order to correlate the different aggregation mechanisms occurring during sol-gel transformation of the studied hybrids with the condensation process of the silicon species that leads to siloxane phase formation and finally gelation, ${ }^{29} \mathrm{Si} \mathrm{NMR}$ measurements have been performed on the dried gels. The ${ }^{29} \mathrm{Si}$ solid state NMR/MAS spectra of dried samples are shown in Fig. 4. All spectra present two bands located around chemical shifts of $-58.0 \pm 0.2$ and $-67.0 \pm 0.2 \mathrm{ppm}$ associated with the presence of $\mathrm{T}^{2}\left(\mathrm{RSi}^{*}(\mathrm{OSi})_{2} \mathrm{OH}\right)$ and $\mathrm{T}^{3}\left(\mathrm{RSi}^{*}(\mathrm{OSi})_{3}\right)$ sites ( $\mathrm{R}$ being an organic motive of the PPO chain), respectively. The relative proportion between $T^{3}$ and $T^{2}$ silicon nuclei was calculated from the integrated area under the NMR bands and also grouped in Table 1. The average condensation degree (Table 1) was calculated from the relative abundance of such silicon nuclei, considering that $\mathrm{T}^{3}$ and $\mathrm{T}^{2}$ entities corresponds to a complete condensation (condensation degree of $100 \%$ ) and a partial condensation (condensation degree of $2 / 3=$ $66.6 \%$ ) of silicon species, respectively.

For $\mathrm{PPO}_{4000}$ both the condensation degree and the $\mathrm{T}^{3} / \mathrm{T}^{2}$ ratio present larger values than those observed in $\mathrm{PPO}_{130}$ of same doping level (Table 1). The condensation degrees of the highest doped $\mathrm{PPO}_{130}$ and $\mathrm{PPO}_{4000}$ hybrids $([\mathrm{O}] /[\mathrm{Li}]=4)$ are

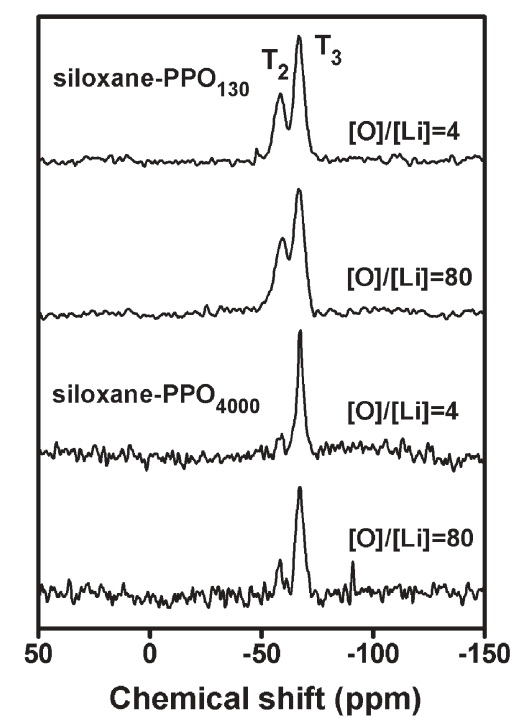

Fig. $4{ }^{29} \mathrm{Si}$ NMR spectra of dried $\mathrm{PPO}_{130}$ and $\mathrm{PPO}_{4000}$ hybrids prepared with $[\mathrm{O}] /[\mathrm{Li}]=4$ and 80 . essentially the same as measured at low doping levels. The $\mathrm{T}^{3} / \mathrm{T}^{2}$ ratio, and consequently the condensation degree of $\mathrm{PPO}_{130}$ composite doped with low lithium concentration $([\mathrm{O}] /[\mathrm{Li}]=80)$, is larger than that observed for undoped samples prepared under the same conditions (Table 1). In summary, these results evidence that the presence of lithium salt in the reaction bath affects the polycondensation reaction of $\mathrm{PPO}_{130}$, while any remarkable doping effect is verified in the $\mathrm{PPO}_{4000}$ nanocomposite.

\section{4 $\mathrm{LiClO}_{4}-$ hybrid interactions}

In order to explain how the lithium salt contents and PPO molecular weight affect the aggregation mechanism of silicon species and the condensation degree of the siloxane phase during hybrids gelation, a study of the evolution of the local structure of the composites and of the doping ions environment during the process has been performed through FTIR spectroscopy and ${ }^{7} \mathrm{Li}$ NMR measurements. We must emphasize that there are three available coordinating sites for the cations in these siloxane-PPO hybrid sols or gels: (1) the ether oxygen atoms of the polymer chains, (2) the carbonyl oxygen atoms of the urea of the cross-links and (3) the perchlorate anion and the water/alcohol solvent molecules.

Fig. 5 presents the evolution over the range $1400-1800 \mathrm{~cm}^{-1}$ (a), 700-1400 $\mathrm{cm}^{-1}$ (b) and $580-660 \mathrm{~cm}^{-1}$ (c) of the FTIR spectra of the low-doped $([\mathrm{O}] /[\mathrm{Li}]=80)$ and high-doped $([\mathrm{O}] /[\mathrm{Li}]=4) \mathrm{PPO}_{130}$ and $\mathrm{PPO}_{4000}$ hybrids during gelation. The spectrum of the undoped $\mathrm{PPO}_{130}$ sample is also presented for comparison and is essentially similar to that of undoped $\mathrm{PPO}_{4000}$ composite (not shown).

Firstly we will analyze the FTIR spectra in the "amide I" (carbonyl stretching, $v_{\mathrm{C}=\mathrm{O}}$, mode) and "amide II" (mixed mode with a major contribution from the $\mathrm{N}-\mathrm{H}$ in-plane bending vibration) region $\left(1800-1500 \mathrm{~cm}^{-1}\right)$ to determine the role played by the carbonyl oxygen atoms of the urea crosslinks, in the coordination of the $\mathrm{Li}^{+}$ions (Fig. 5a). The spectra of the initial sol of the undoped hybrid shows the presence of an intense band located at $1641 \mathrm{~cm}^{-1}$ (Fig. 5a) which has already been observed in siloxane-poly(oxyethylene) (PEO) hybrids and unambiguously attributed to the existence of high ordered urea-urea associations through hydrogen bonding. ${ }^{29}$ For the undoped and low-doped samples this band do not present significant evolution during gelation, but a splitting of this band is observed for hybrids doped with high lithium concentration $([\mathrm{O}] /[\mathrm{Li}]=4)$. This behavior suggests the breaking of urea-urea bonds by lithium ions at high doping levels, due to the interaction of lithium with the carbonyl oxygen atoms of the urea linkages. However, the presence of lithium ions coordinated to urea groups also occurs at lowdoping level as attested by the absence of the band located at $1720 \mathrm{~cm}^{-1}$, already observed in siloxane-PEO hybrids and attributed to disordered $\mathrm{PEO}-$ urea association, ${ }^{29}$ in the spectra of low-doped $\mathrm{PPO}_{130}$ and $\mathrm{PPO}_{4000}$ hybrids (Fig. 5a). The breaking of such hydrogen bonds between the polymer chains and the urea groups also occurs for the highest doped $\mathrm{PPO}_{4000}$ composite. It is interesting to note that no free urea groups are present in the hybrid sols, whatever the PPO molecular weight or the lithium doping level, as attested by the absence of the 


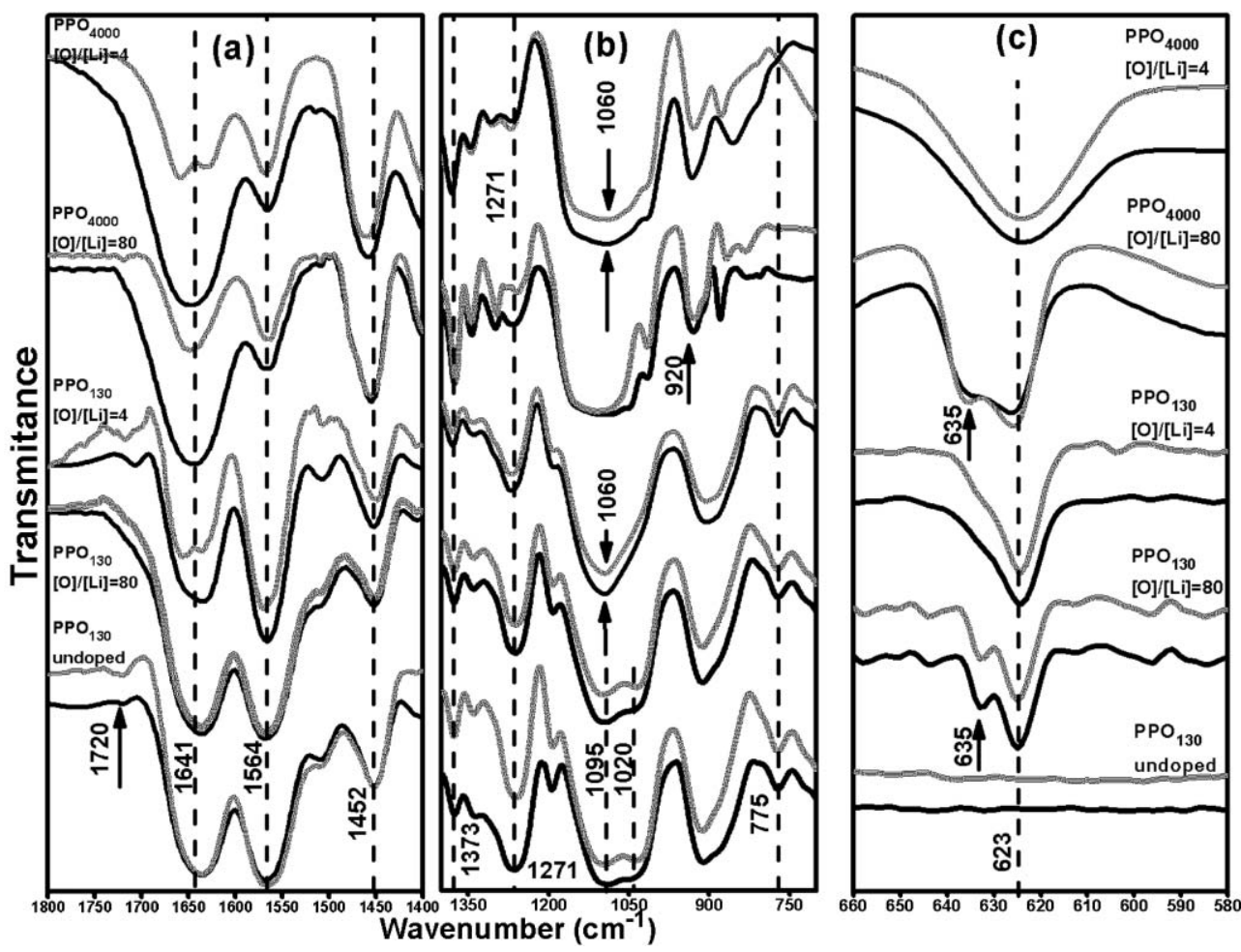

Fig. 5 Selected FTIR spectra measured during sol-gel transition in the amide I and II (a), PPO skeleton $\mathrm{COC}$ stretching (b) and $\mathrm{ClO}_{4}{ }^{-}$stretching (c) regions. The black and grey continuous lines indicate the initial sol and wet gel of the hybrids, respectively.

band located at $1751 \mathrm{~cm}^{-1}$ characteristic of this feature. ${ }^{29}$ Fig. 5a also exhibits, for all samples, two main bands at 1564 and $1452 \mathrm{~cm}^{-1}$ attributed to amide II groups of the urea crosslinks and $\mathrm{CH}_{2}$ scissoring and $\mathrm{CH}_{3}$ deformation, respectively. ${ }^{30}$ These bands do not suffer significant changes during gelation.

To probe the coordination of the $\mathrm{Li}^{+}$ions by the ether oxygen atoms of the PPO we will seek in the region characteristic of the skeleton COC stretching modes (1190$1050 \mathrm{~cm}^{-1}$ interval) spectral changes during sol gel transition of undoped and doped $\mathrm{PPO}_{4000}$ and $\mathrm{PPO}_{130}$ (Fig. 5b). The broad band located at $1095 \mathrm{~cm}^{-1}$ and the shoulder at $1020 \mathrm{~cm}^{-1}$ observed in the spectra of undoped hybrids, were attributed to the stretching vibration of the $\mathrm{CO}$ bonds and to a mixture of $\mathrm{CO}$ stretching, $\mathrm{CC}$ stretching and $\mathrm{CH}_{2}$ rocking in PPO monomers. ${ }^{30}$ This structure was also observed for both low-doped hybrids, while at high lithium contents gelation favours the formation of an unique broad band around $1060 \mathrm{~cm}^{-1}$. This trend suggests that at high lithium concentrations, the cations also interact with the ether-type oxygen of the polymer chains.

Fig. $5 \mathrm{~b}$ also shows, for all samples, two other bands related to urea crosslinks, such as observed at 1373 and $1271 \mathrm{~cm}^{-1}$, which can be attributed to $\mathrm{CH}_{2}$ wagging and interaction between amide III groups, respectively. ${ }^{30} \mathrm{An}$ interesting feature concerns the absence of the band located at $775 \mathrm{~cm}^{-1}$ in the spectra of all $\mathrm{PPO}_{4000}$ composites and the shift towards larger frequency of the band located around $920 \mathrm{~cm}^{-1}$. As the former is associated to amide VI mode of the urea groups and the latter is only observed in "liquid" PEO or $\mathrm{PPO}^{30}$ we conclude that these trends are due to the lower number of urea crosslinks of these hybrids as compared to $\mathrm{PPO}_{130}$ one.

To investigate the role played by the perchlorate in the cation coordination process we analysed the characteristic symmetric stretching vibration mode $\left(v_{4}\right)$ of the $\mathrm{ClO}_{4}{ }^{-}$ion. Salomon et al..$^{31}$ have reported the existence of a pair of bands at 623 and $635 \mathrm{~cm}^{-1}$ in $\mathrm{LiClO}_{4}^{-}$-doped poly(ethers). The first one was assigned to the solvent-separated ions pairs $\mathrm{Li}^{+} \ldots \mathrm{ClO}_{4}{ }^{-}$, or solvent separated dimers of $\mathrm{ClO}_{4}{ }^{-}$, and the second one to the presence of contact ion pairs. Fig. 5c shows the presence of these two bands in the spectrum of low-doped siloxane- $\mathrm{PPO}_{130}$ and siloxane- $\mathrm{PPO}_{4000}$, revealing the presence of solvent-separated and contact ions pairs in these systems. At high doping level $([\mathrm{O}] /[\mathrm{Li}]=4)$ only the band related to solvent-separated ion pairs $\left(623 \mathrm{~cm}^{-1}\right)$ was observed for both hybrids (Fig. 5c).

Quantitative information about the partition of different cation species present in the siloxane-PPO hybrid sols and gels was obtained from ${ }^{7} \mathrm{Li}$ NMR. Fig. 6 presents the evolution of the ${ }^{7} \mathrm{Li}$ NMR spectra during gelation of low-doped $([\mathrm{O}] /[\mathrm{Li}]=$ 80) and high-doped $([\mathrm{O}] /[\mathrm{Li}]=4) \mathrm{PPO}_{130}$ and $\mathrm{PPO}_{4000}$ hybrid sols. All spectra show a broad band with several shoulders, corresponding to convolution of the resonance of different lithium species in the gelling system. In order to determine the nature of these species ${ }^{7} \mathrm{Li}$ NMR measurements were performed in reference samples (commercial PPO, water, ethanol and commercial urea) containing lithium perchlorate. The comparison between the spectra of the reference samples (not shown) and of the siloxane-PPO hybrids (Fig. 6) allowed us to attribute the subpeaks located around $0 \mathrm{ppm}$ and between -0.1 and $-0.3 \mathrm{ppm}$ to lithium cations solvated 

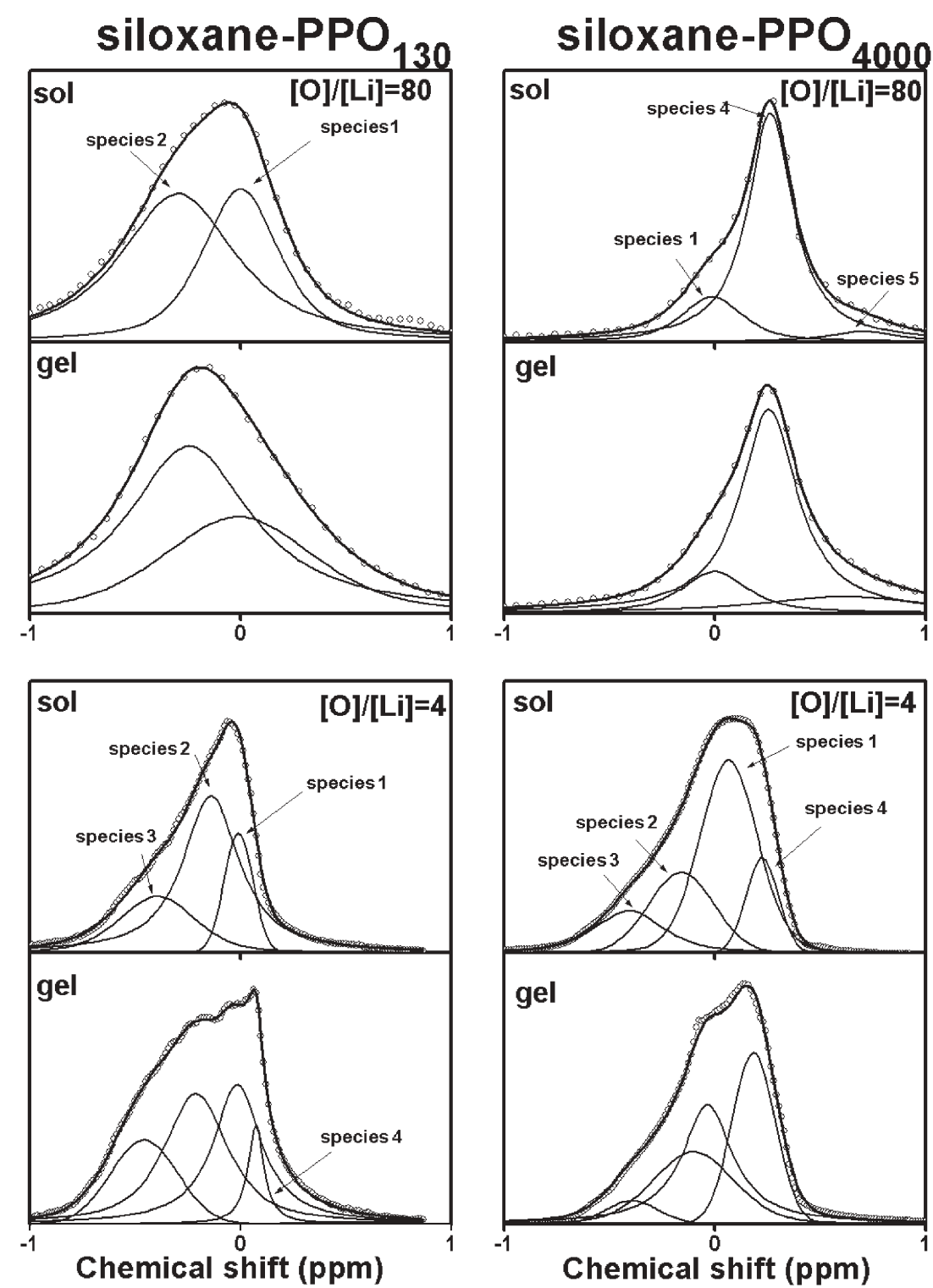

Fig. 6 Evolution of the ${ }^{7} \mathrm{Li}$ NMR spectra during mean step of gelation of lithium-doped $([\mathrm{O}] /[\mathrm{Li}]=4$ and 80$) \mathrm{PPO}_{130}$ and $\mathrm{PPO}_{4000}$ hybrids. The solid line following the experimental data is the sum of individual sub-peaks.

by water molecules (named as species 1) and interacting with urea groups (species 2), respectively. Furthermore, the subpeak located between -0.4 and $-0.7 \mathrm{ppm}$ could be attributed to lithium cations coordinated by ether-type oxygen of the PPO chains (species 3). Since the spectral signature of lithium solvated by ethanol molecules appears around $-0.8 \mathrm{ppm}$ and since infrared measurements have shown the absence of contact ion pairs in high-doped hybrid sols, we attributed the subpeaks located around $0.2 \mathrm{ppm}$ to solvent-separated ion pairs (species 4). Therefore, the subpeak located between 0.6 and 0.7 ppm appearing in the spectrum of low-doped $\mathrm{PPO}_{4000}$ composite could be attributed to contact ion pairs (species 5), detected by infrared spectroscopy.

Fig. 7 shows, for all hybrid sols, the evolution of the fraction number of species 1, 2, 3, 4 and 5 during the gelation, determined from the area of the different subpeaks that appear in the NMR spectra. For low and high doped siloxane- $\mathrm{PPO}_{130}$ samples the proportion of each species does not present important changes during the sol-gel transformation, except the formation of species 4 for $\alpha>0.5$ in the case of the high-doped $\mathrm{PPO}_{130}$, resulting in a low decrease of the proportion of species 2 . Note that in the latter sol, more than half of the total species consists on lithium ions coordinated to urea groups (species 2).

For low-doped siloxane- $\mathrm{PPO}_{4000}$ hybrids $([\mathrm{O}] /[\mathrm{Li}]=80$, Fig. 7) a continuous increase of the fraction of contact ion pairs (species 5) and a consequent decrease of the proportion of solvent separated ion pairs (species 4) are observed during gelation. However, species 4 represent around $70 \%$ of the total lithium species during the whole gelation process. For the high-doped $\mathrm{PPO}_{4000}$ composite a pronounced decrease of the proportion of lithium ions coordinated to ether-type oxygen (species 3 ) and solvated by water molecules (species 1) occurs during the process, whereas the proportion of solvent separated ion pairs (species 4) increases significantly. 

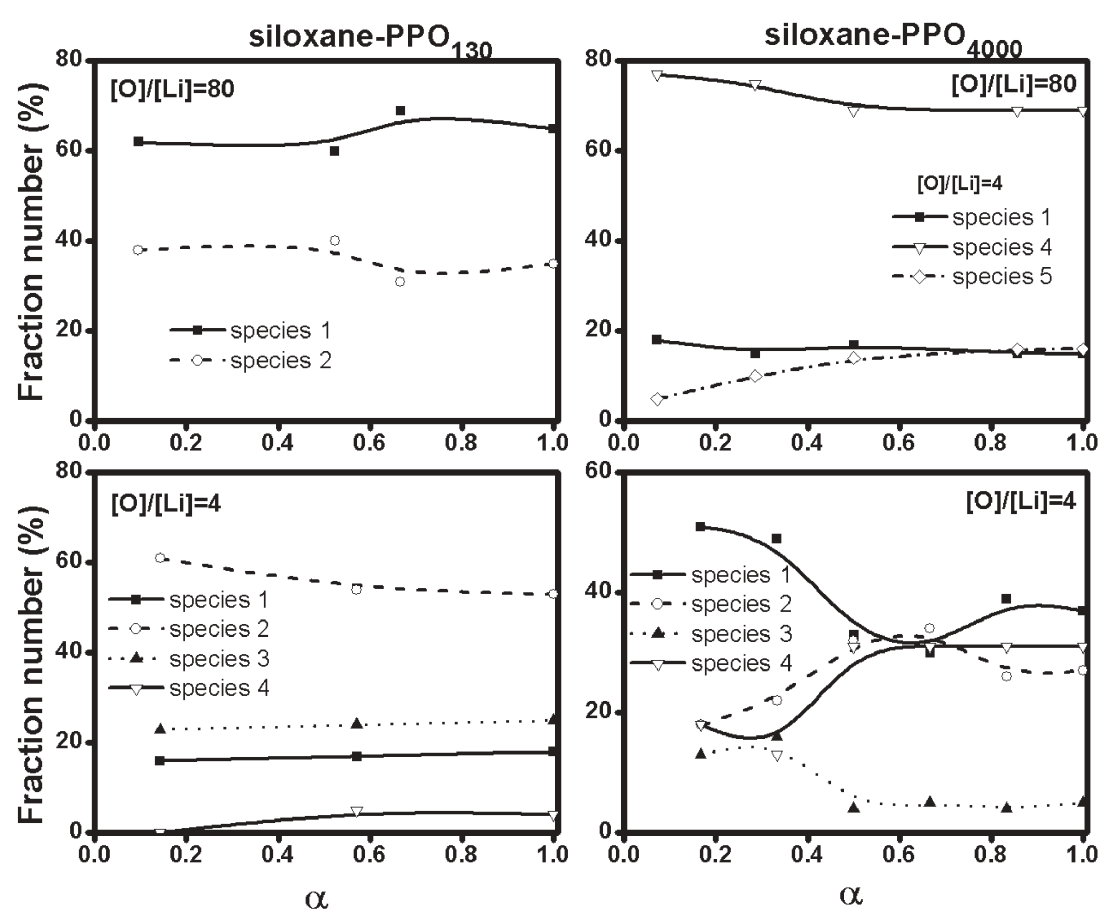

Fig. 7 Evolution of the fraction of lithium species during sol gel transition of $\mathrm{PPO}_{130}$ and $\mathrm{PPO}_{4000}$ hybrids prepared with $[\mathrm{O}] /[\mathrm{Li}]=4$ and 80 .

\section{Discussion}

This study has revealed that addition of lithium salts does not affect the aggregation mechanism of siloxane-PPO sols containing polymers of low $\left(130 \mathrm{~g} \mathrm{~mol}^{-1}\right)$ and high $\left(4000 \mathrm{~g} \mathrm{~mol}^{-1}\right)$ molecular weight in the same way. While for $\mathrm{PPO}_{130}$ hybrids, the breaking of urea-PPO and urea-urea interactions by lithium salt addition and the number of lithium atoms available to interact with the different coordination sites determine the nature of the aggregation mechanism, and consequently the condensation degree of the resulting dried gel, in $\mathrm{PPO}_{4000}$ hybrids the only parameter determining gelation mechanisms seems to be the viscosity of the sols.

In $\mathrm{PPO}_{130}$ hybrids the number of urea groups forming crosslinks between PPO chains and siloxane particles is much larger than in $\mathrm{PPO}_{4000}$ composites. Therefore, we expected for $\mathrm{PPO}_{130}$ hybrids a large number of urea-urea and PPO-urea interactions in the undoped dried gel, as already observed in similar siloxane-PEO xerogel. ${ }^{29}$ The present study reveals, for the first time, the existence of such interactions also in the liquid state during overall steps of sol-gel transformation. Furthermore, it reveals that such interactions also exist in undoped $\mathrm{PPO}_{4000}$ hybrids sols, in which the number of urea groups is significantly lower.

For both PPO molecular weight small addition of lithium $([\mathrm{O}] /[\mathrm{Li}]=80)$ leads to the breaking of PPO-urea interactions, as revealed by infrared spectroscopy (Fig. 6a). Such behaviour has already been observed in solid dried gels of siloxane-PEO doped with europium perchlorate. ${ }^{32}$ However, our study reveals that the occurrence of this process in the liquid sol, also observed for the first time, has important consequences on the aggregation mechanism responsible for the wet gel formation from $\mathrm{PPO}_{130}$ sols.
As a matter of fact, for $\mathrm{PPO}_{130}$ sols, the change in aggregation mechanism from RLCCA for the undoped sample to DLMCA for the low-doped one, observed at the first stages of the gelation process, should be explained by the breaking of PPO-urea interactions by lithium salt addition. The existence of PPO-urea interactions implies the presence of one or several segments of PPO chains around the urea groups, which are very close to reactive silicon species. The presence of supramolecular interaction in the undoped hybrid should decrease the efficiency of polycondensation reactions, due to steric factors hindering the contact with silicon species belonging to other chains. Furthermore, the supramolecular interaction between urea groups and PPO chains should decrease the mobility of reactive silicon species located at chain ends. On the other hand, the efficiency of hydrolysis reactions should not be affected by the existence of such interactions, since do not depend on contact probability between silicon species but of water amount available in the sol. All these factors should leads to a rate of condensation smaller than hydrolysis rate favouring the RLCCA mechanism.

The breaking of PPO-urea interactions by addition of small amount of lithium salt through the coordination of lithium ions to the carbonyl oxygen of urea groups should favour the efficiency of polycondensation as evidenced by ${ }^{29} \mathrm{Si}$ NMR (Fig. 4 and Table 1). The larger condensation degree of the low-doped $\mathrm{PPO}_{130}$ hybrid xerogel compared to the undoped sample is consistent with the occurrence of DLMCA mechanism revealed by the rheological behaviour (Table 1), which leads to the formation of highly condensed and compact fractal aggregates $(D=2.4)$. Another important point revealed by FTIR and ${ }^{7} \mathrm{Li}$ NMR results is the absence of lithium ions interacting with ether-type oxygen of PPO in the low-doped siloxane- $\mathrm{PPO}_{130}$ hybrid sol and wet gel. This 
illustrates the greater chemical affinity of lithium ions with carbonyl oxygen of urea groups compared with the ether-type oxygen of PPO. Furthermore, at this low doping level the amount of ion pairs (detected by FTIR) should be extremely low, since ${ }^{7} \mathrm{Li}$ NMR has not detected it.

In the case of high doped $\mathrm{PPO}_{130}$ sols the existence of PPOurea interactions and of breaking of urea-urea interactions has been detected by FTIR spectroscopy. The existence of ureaurea interactions implies the motion of aggregates constituted of at least two hybrid precursor molecules whose mobility should be significantly lower than individual molecules, which should explain the occurrence of a cluster-cluster aggregation mechanism (DLCCA) in the first stages of gelation of this sample. Since for $\mathrm{PPO}_{130}$ hybrids the number of oxygen atoms located in urea groups is similar to the number of ether-type oxygen, a similar proportion of urea-urea and PPO-urea interactions is expected in an undoped hybrid sol. However, our experimental results reveal that the breaking of PPO-urea interactions by lithium doping is more efficient to induce monomer-cluster aggregation and polycondensation than breaking of urea-urea interactions. In fact, the occurrence of DLCCA mechanism leading to a lower $D$ value should lead to the formation of hybrid aggregates of lower density and compactness than that of low-doped $\mathrm{PPO}_{130}$ hybrid, which is not apparent in ${ }^{29} \mathrm{Si}$ NMR results of the dried gel (Table 1). This apparent inconsistency should be explained by the fact that, as shown by rheological measurements, DLCCA mechanisms essentially occurs at the first stages of the gelation process and a high efficiency of polycondensations reactions between silicon species should be favoured at the following stages by the presence of $\mathrm{Li}^{+}-\mathrm{O}-\mathrm{Li}^{+}$crosslinks between ethertype oxygen of the polymer chains, inducing an approximation between the chains and consequently of the silicon species located at their extremities. This hypothesis is consistent with the presence of lithium cations coordinated by ether-type oxygen of PPO detected by infrared and ${ }^{7} \mathrm{Li}$ NMR measurements. At last, the much larger proportion of lithium ions interacting with carbonyl oxygen of urea groups compared to ether-type oxygen of PPO chains in the highest-doped $\mathrm{PPO}_{130}$ hybrid can be explained both by the greater affinity of lithium with carbonyl oxygen, already observed at low doping levels, and the absence of breaking of PPO-urea interactions in the studied sample.

The occurrence of a diffusion-limited aggregation mechanism for all $\mathrm{PPO}_{4000}$ hybrids, independent of lithium content, can be related to the larger viscosity of the hybrid sol containing longer PPO chains as compared to $\mathrm{PPO}_{130}$ composites. As a matter of fact, in a diffusion-limited aggregation (DLMCA or DLCCA) the monomers travel by random walks and stick irreversibly at first contact on a growing cluster. ${ }^{19}$ This process is obviously favoured when the motions of potentially reacting species are slow due to the high viscosity of the medium. An important consequence of DLMCA is the high condensation degree observed for all $\mathrm{PPO}_{4000}$ hybrids whatever the lithium content (Table 1). In fact, the mechanism prevalent at the first stages of gelation of the $\mathrm{PPO}_{4000}$ hybrid does not seem to be sensitive to chemical factors, but is essentially governed by the sol viscosity. The preponderant role of viscosity in these samples is confirmed by the shift towards larger frequency of the band located around $920 \mathrm{~cm}^{-1}$ (Fig. 5b) observed during gelation of undoped and low-doped sols or immediately after preparation of the most doped one. Since the presence of this band reveals the presence of "liquid" PPO of high mobility, this shift shows the strong viscous character of the PPO chains in all hybrids containing long PPO chains. Furthermore, the high viscosity of $\mathrm{PPO}_{4000}$ hybrids should also favour the formation of an important proportion of $\mathrm{Li}^{+} \cdots \mathrm{ClO}_{4}{ }^{-}$ion pairs observed at low doping level in these systems, by making more difficult ions separation and decreasing ions mobility. Again, the greater affinity of lithium ions with carbonyl oxygen than with ether-type oxygen is confirmed by the larger fraction of cations interacting with urea at high doping level, revealed by NMR spectroscopy (Fig. 7).

Another interesting point is the consistency between the aggregation models proposed from the fractal dimensionality and the measured gelation time. For undoped and high-doped samples, the shortest gelation time is obtained when the first period of gelation is governed by a diffusion-limited monomer-cluster aggregation (DLMCA, Table 1). This behaviour was expected because in such mechanism polycondensations reactions between silicon species of the hybrid precursor have a greater probability to occur and consequently, the gelation time is smaller than observed for cluster-cluster aggregation processes. The difference in gelation time between $\mathrm{PPO}_{130}$ and $\mathrm{PPO}_{4000}$ is less pronounced at low doping level, because the aggregation mechanism is the same (DLMCA) for both samples.

\section{Conclusion}

Linear growth, fractal growth and percolation models allowed us to describe gelation of undoped and lithium-doped siloxane-PPO hybrids sols at different stages of the process. The aggregation mechanisms involved in the first gelation stages of hybrids containing polymer of low molecular weight $\left(130 \mathrm{~g} \mathrm{~mol}^{-1}\right)$ are directly related to the presence or breaking of PPO-urea interactions in the liquid sol, while cluster-cluster aggregation and formation of less polycondensed silicon species are favoured by the existence of PPO-urea interactions in the undoped composites. The breaking of these interactions by addition of small lithium amounts induces a monomercluster aggregation and a large efficiency of polycondensation reactions. In opposition, the breaking of urea-urea interactions does not promote monomer-cluster aggregation, as revealed by the rheological behaviour of high doped siloxane$\mathrm{PPO}_{130}$ composite.

The aggregation mechanisms in the first gelation stages of hybrids containing longer polymer chains (4000 $\mathrm{g} \mathrm{mol}^{-1}$ ) are independent of lithium content and are governed by the larger value of the viscosity, which imposes the occurrence of a diffusion-limited monomer-cluster aggregation.

For all samples, after the initial period of formation of branched molecules presenting fractal structures, the interconnection of isolated aggregates forms the percolating network of the wet gels. This interconnection and a large polycondensation efficiency is favoured at high doping level by the formation of crosslinks $\mathrm{O}-\mathrm{Li}^{+}-\mathrm{O}$ between cations and 
ether-type or carbonyl-type oxygen of different PPO chains belonging to different fractal aggregates.

Finally, the dependence of the aggregate growth mechanism of siloxane-PPO hybrid on the lithium salt doping level allows us to better understand the change in the structure of nanocomposite, that must be considered in future attempts to obtain a complete picture of the relationship between the ionic mobility and structure of this class of solid electrolyte. In spite of these studies have been focused on siloxane-poly(oxypropylene) hybrids, similar effects of poly(ether) chain length and of doping level are expected for other hybrids material of the siloxane-poly(ether) family doped with different alkaline salts.

\section{Acknowledgements}

We acknowledge Silvia. H. Santagneli for help in NMR measurements and the Brazilian Agencies FAPESP, CNPq and CAPES for financial support.

\section{References}

1 H. H. Winter and F. Chambon, J. Rheol., 1986, 30, 367.

2 B. Gauthier-Manuel, E. Guyon, S. Roux and F. Lefaucheux, J. Phys., 1987, 48, 869.

3 J. Scanlan and H. H. Winter, Macromolecules, 1991, 24, 47.

4 L. R. B. Santos, C. V. Santilli and S. H. Pulcinelli, J. Non-Cryst. Solids, 1999, 247, 153.

5 O. Van Cantford, A. Brasseur, B. Michaux, R. Pirard and J. P. Pirard, Faraday Discuss., 1995, 101, 265.

6 J. Wen and G. L. Wilkes, Chem. Mater., 1996, 8, 1667.

7 P. Lacan, C. Guizard and L. Cot, J. Sol-Gel Sci. Tech., 1995, 4, 151.

8 S. R. Raghavan, H. J. Walls and S. A. Khan, Langmuir, 2000, 16, 7920.

9 K. Dahmouche, P. H. de Souza, T. J. Bonagamba, H. Paneppucci, P. Judeinstein, S. H. Pulcinelli and C. V. Santilli, J. Sol-Gel Sci. Technol., 1998, 13, 909.

10 K. Dahmouche, C. V. Santilli, S. H. Pulcinelli and A. F. Craievich, J. Phys. Chem. B, 1999, 103, 492.
11 J. A. Chaker, K. Dahmouche, C. V. Santilli, V. Briois, S. H. Pulcinelli and P. Judeinstein, J. Sol-Gel Sci. Technol., 2003, 26, 1075.

12 J. A. Chaker, K. Dahmouche, C. V. Santilli, S. H. Pulcinelli, V. Briois, P. Judeinstein and A. F. Craievich, J. Eur. Ceram. Soc., 2005, 25, 2617.

13 V. De Zea Bermudez, D. Baril, J. Y. Sanchez, M. Armand and C. Poinsignon, Proc. SPIE-Int. Soc. Opt. Eng., 1992, 1728, 180.

14 P. Judeinstein and H. Schmidt, J. Sol-Gel Sci. Technol., 1994, 3, 189.

15 C. O. Avellaneda, K. Dahmouche and L. O. S. Bulhões, Mol. Cryst. Liq. Cryst., 2002, 374, 113.

16 V. H. V. Sarmento, K. Dahmouche, C. V. Santilli and S. H. Pulcinelli, J. Non-Cryst. Solids, 2002, 304, 134.

17 E. J. A. Pope and J. D. Mackenzie, J. Non-Cryst. Solids, 1988, 101, 198.

18 P. G. de Gennes, J. Phys., 1976, 37, L1.

19 J. C. Brinker and G. W. Scherer, Sol-Gel Science: The Physics and Chemistry of Sol-Gel Processing, Academic Press, New York, 1990, pp. 191-203.

20 A. Izuka, H. H. Winter and T. Hashimoto, Macromolecules, 1997, 30, 6158.

21 S. Ross, Rheol. Acta, 1991, 31, 401.

22 D. S. Cannel and C. Aubert, in On Growth and Form, ed. H. E. Stanley and N. Ostrowsky, Nijhoff, Boston, 1986, p. 187.

23 H. H. Winter and F. Chambon, J. Rheol., 1987, 31, 683.

24 E. Rude, J. L. Lorens and C. Mans, in Progress and Trends in Rheology, Proceeding of the fifth European Rheology Conference, 1998, 613.

25 K. Dahmouche, C. V. Santilli, J. A. Chaker, S. H. Pulcinelli and A. F. Craievich, Jpn. J. Appl. Phys, 1999, 38, 172.

26 M. D. Bertchold, R. D. Vest and L. Plambeck, Jr., J. Am. Chem. Soc., 1968, 90, 4590 .

27 P. J. Flory, J. Am. Chem. Soc., 1943, 65, 372.

28 D. T. Mallin, J. C. W. Chien and H. H. Winter, Macromolecules, 1991, 94, 850

29 S. C. Nunes, V. de Zea Bermudez, D. Ostrovski and L. D. Carlos, J. Mol. Struct., 2004, 702, 39.

30 V. De Zea Bermudez, L. D. Carlos and L. Alcacer, Chem. Mater., 1999, 11, 569.

31 M. Salomon, M. Xu, E. M. Eyring and S. J. Petrucci, J. Phys. Chem., 1994, 98, 8234.

32 V. de Zea Bermudez, R. A. Sa Ferreira, L. D. Carlos, C. Molina, K. Dahmouche and S. J. L. Ribeiro, J. Phys. Chem. B., 2001, 105, 3378. 